\title{
Computerized interpretation of the prehospital electrocardiogram: predictive value for ST segment elevation myocardial infarction and impact on on-scene time
}

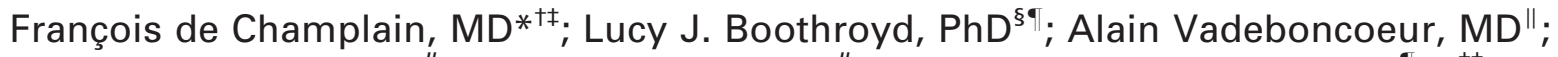 \\ Thao Huynh, MD, MSc ${ }^{\#}$; Viviane Nguyen, MD*; Mark J. Eisenberg, MD, MPH ${ }^{\top *}{ }^{\dagger+}$;

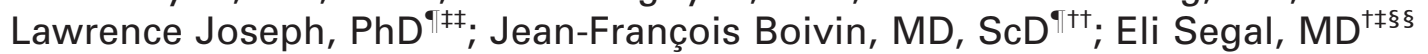

\section{ABSTRACT}

Introduction: Computerized interpretation of the prehospital electrocardiogram (ECG) is increasingly being used in the basic life support (BLS) ambulance setting to reduce delays to treatment for patients suspected of ST segment elevation myocardial infarction (STEMI).

Objectives: To estimate 1) predictive values of computerized prehospital 12-lead ECG interpretation for STEMI and 2) additional on-scene time for 12-lead ECG acquisition.

Methods: Over a 2-year period, 1,247 ECGs acquired by primary care paramedics for suspected STEMI were collected. ECGs were interpreted in real time by the GEMarquette 12SL ECG analysis program. Predictive values were estimated with a bayesian latent class model incorporating the computerized ECG interpretations, consensus ECG interpretations by study cardiologists, and hospital diagnosis. On-scene time was compared for ambulance-transported patients with ( $n=985)$ and without $(n=5,056)$ prehospital ECGs who received prehospital aspirin and/or nitroglycerin. Results: The computer's positive and negative predictive values for STEMI were $74.0 \%(95 \%$ credible interval [Crl] 69.6-75.6) and $98.1 \%(95 \% \mathrm{Crl} 97.8-98.4)$, respectively. The sensitivity and specificity were $69.2 \%(95 \% \mathrm{Crl} 59.0-78.5)$ and 98.9\% (95\% Crl 98.1-99.4), respectively. Prehospital ECGs were associated with a mean increase in on-scene time of 5.9 minutes (95\% confidence interval 5.5-6.3).

Conclusions: The predictive values of the computerized prehospital ECG interpretation appear to be adequate for diversion programs that direct patients with a positive result to hospitals with angioplasty facilities. The estimated $26.0 \%$ chance that a positive interpretation is false is likely too high for activation of a catheterization laboratory from the field. Acquiring prehospital ECGs does not substantially increase on-scene time in the BLS setting.

\section{RÉSUMÉ}

Introduction: On a de plus en plus recours à l'interprétation informatisée de l'électrocardiogramme (ECG) en phase préhospitalière, dans les ambulances de réanimation cardiorespiratoire (RCR) élémentaire, afin de réduire le temps $\mathrm{d}^{\prime}$ attente avant le traitement chez les patients souffrant probablement d'un infarctus du myocarde avec sus-décalage du segment ST (IM+ST).

Objectifs: L'étude visait à évaluer: 1) les valeurs prévisionnelles de l'interprétation informatisée de l'électrocardiogramme (ECG) à 12 dérivations en phase préhospitalière dans les cas d'IM+ST; et 2) le temps supplémentaire passé sur place pour obtenir I'ECG à 12 dérivations.

Méthodes: Sur une période de 2 ans, 1247 ECG ont été effectués par des ambulanciers paramédicaux en soins primaires, dans des cas présumés d'IM+ST. Les ECG ont été interprétés en temps réel, selon le programme d'analyse GE-Marquette 12SL. L'estimation des valeurs prévisionnelles reposait sur un modèle de classification bayésienne à variables latentes, auquel avaient été intégrés les interprétations informatisées de I'ECG, les interprétations consensuelles de I'ECG fournies par les cardiologues participant à

From the *Department of Emergency Medicine, McGill University Health Centre, Montreal General Hospital; †Department of Family Medicine, McGill University; ‡Corporation d’Urgences-santé; §Institut national d'excellence en santé et en services sociaux (INESSS); †Department of Epidemiology, Biostatistics and Occupational Health, McGill University; || Department of Emergency Medicine, Montreal Heart Institute; \#Department of Cardiology, McGill University Health Centre; **Division of Cardiology, Jewish General Hospital; †+Centre for Clinical Epidemiology and Community Studies, Lady Davis Research Institute for Medical Research, Jewish General Hospital; ‡‡Department of Clinical Epidemiology, McGill University Health Centre; and $\S \S$ Department of Emergency Medicine, Jewish General Hospital, Montreal, QC.

Correspondence to: Dr. François de Champlain, Department of Emergency Medicine, Montreal General Hospital, 1650 Cedar Avenue, Room B2.117, Montreal, QC H3G 1A4; francois.de_champlain@mcgill.ca

This article has been peer reviewed. 
I'étude et les diagnostics posés à l'hôpital. II y a eu aussi une comparaison du temps passé sur place chez les patients transportés en ambulance, ayant été soumis $(n=985)$ ou non soumis ( $n=5056$ ) à un ECG en phase préhospitalière et ayant reçu de I'acide acétylsalicylique (AAS) et/ou de la nitroglycérine en phase préhospitalière.

Résultats: Les valeurs prévisionnelles informatisées positive et négative de I'ECG en phase préhospitalière à l'égard de $\mathrm{I}^{\prime} \mathrm{IM}+\mathrm{ST}$ se sont établies à $74.0 \%$ (intervalle de crédibilité [ $\left.\mathrm{ICr}\right]$ à 95\%: 69.6-75.6) et à 98.1\% ( $\mathrm{ICr}$ à 95\%: 97.8-98.4), respectivement. La sensibilité et la spécificité ont atteint 69.2\% (ICr à 95\%: 59.0-78.5) et 98.9\% (ICr à 95\%: 98.1-99.4), respectivement. Les ECG en phase préhospitalière ont été associés à une augmentation moyenne de 5.9 minutes (intervalle de confiance à 95\%: 5.5-6.3) du temps passé sur place.
Conclusions: Les valeurs prévisionnelles de l'interprétation informatisée de l'ECG en phase préhospitalière semblent adéquates en ce qui concerne les programmes de déroutement des ambulances vers les hôpitaux dotés des installations nécessaires à l'angioplastie pour les patients ayant obtenu des résultats positifs. Par contre, le risque de fausse interprétation positive, estimé à $26.0 \%$, est probablement trop élevé pour justifier la mise en action d'un laboratoire de cathétérisme, fondée sur les données recueillies sur place. L'obtention de I'ECG en phase préhospitalière n'a pas pour effet d'augmenter sensiblement le temps passé sur place dans le contexte de la RCR.

Keywords: electrocardiogram, on-scene time, predictive value, prehospital, ST segment elevation myocardial infarction
The prehospital electrocardiogram (ECG) is used to decrease treatment delays and improve outcomes for patients with acute ST segment elevation myocardial infarction (STEMI) ${ }^{1,2}$ by alerting hospitals from the field or by directing ambulances to angioplasty facilities. Although 12-lead ECGs can be acquired by primary care paramedics providing basic life support (BLS), interpretation is a more complex issue. Our Canadian province of Quebec (7.8 million persons) is almost entirely served by BLS paramedics who do not interpret ECGs. Quebec has equipped ambulances with the GE-Marquette 12 SL ECG analysis program (GE Medical Systems, Milwaukee, WI), one of the most common diagnostic software programs used by ambulance operators. ${ }^{3}$ The criteria for acquiring prehospital ECGs are fairly broad (not only chest pain); thus, the prevalence of STEMI is likely to be low. The predictive values of this software-the probabilities of a test-positive patient actually having STEMI and of a test-negative patient not having STEMI-in such a setting are unclear. Some studies suggest that a substantial proportion of computerpositive patients may not be later diagnosed with STEMI. ${ }^{3,4}$

Another issue is how long it takes to acquire a prehospital ECG because lengthy "on-scene" time can be unsafe and potentially outweighs the time savings from having diagnostic information sooner. Estimates vary from 1.2 to 7 minutes for advanced life support (ALS) personnel, combined ALS and BLS teams, or ambulance physicians, ${ }^{5-12}$ with one BLS estimate of 5 minutes in the literature. ${ }^{13}$ Our first objective was to estimate predictive values of computerized ECG interpretation for STEMI in the BLS setting. The second objective was to estimate additional time spent on scene.

\section{METHODS}

\section{Study design}

We collected prehospital ECG tracings acquired by primary care paramedics and run-time data for the period January 1, 2005, to December 31, 2006. Study cardiologists provided retrospective consensus interpretation of the tracings, and we obtained a hospital diagnosis for each patient, whether or not the patient was eventually admitted. We focused our test performance analysis on predictive values because these statistics are more interpretable and less abstract in the field setting, where the real disease status is unknown. Predictive values of the computerized ECG interpretation were estimated using a bayesian latent class model..$^{14,15}$ In bayesian analysis of a diagnostic test, "prior" information about the test's performance (e.g., from the literature) is combined with observed data to produce a "posterior" estimate with credible intervals. Unlike standard confidence intervals, credible intervals allow direct statements about the probability of values within a certain range, which is particularly useful for policy makers.

The Appendix provides further details about our bayesian analysis. Briefly, our model allowed for evolution of the ST segment over time using two latent variables representing the patient's status in the field and in hospital. The computerized interpretations, the consensus cardiologist interpretations, and the hospital diagnoses were considered simultaneously, 
as three tests. There was no comparison against a gold standard because all tests were considered imperfect. The model also estimated STEMI prevalence in the tested population and test sensitivity and specificity, all of which impact predictive value. ${ }^{3}$ To address our second objective, we took advantage of the fact that during the study period, about one-third of the ambulance fleet was equipped with ECG machines, allowing comparison of patients with and without ECGs. The study was approved by the institutional ethics board at the Montreal Heart Institute. The hospital chart data were requested according to established quality assurance protocol and did not require patient consent in accordance with the Loi sur l'accès aux documents des organismes publics (L.R.Q., c. A-2.1, a. 125).

\section{Study setting and population}

Standard 12-lead ECGs were acquired by primary care paramedics with Zoll M Series monitor-defibrillators in metropolitan Montreal-Laval (2.3 million persons over $744 \mathrm{~km}^{2}$, served by one ambulance operator). Paramedics $(n=205)$ received a 4-hour training session on ECG acquisition in May-June 2003 and occasional refresher instruction thereafter on a volunteer basis. Each paramedic was met every 4 months to see if he or she had questions about the ECG protocol. Our ECG data collection thus started 18 months after initial training. ECGs were acquired at the patient encounter site unless done in a stationary ambulance for safety or privacy. Tracings were collected at the ambulance operational centre (the first was used for analysis, in the case of multiple testing). Although not all ambulances were equipped with ECG machines, the emergency call (911) operators did not dispatch vehicles according to ECG capability.

Inclusion criteria for ECG acquisition were chest pain of suspected cardiac origin, or anginal equivalents, for at least 20 minutes and either 1) age 35 years or older or 2) age 18 years or older with a history of coronary artery disease. Anginal equivalents were dyspnea, epigastric pain, or noncontinuous chest pain for more than 12 hours. Exclusion criteria were 1) diminished level of consciousness ("V," "P," or "U" on the AVPU [Alert, responds to Voice, responds to Pain, Unresponsive] scale); 2) heart rate $<50$ or $>$ 150 beats/min; 3) systolic blood pressure $<100 \mathrm{~mm}$ $\mathrm{Hg}$; and 4 ) oxygen saturation $<92 \%$ on room air.
Paramedics were instructed to acquire the ECG before giving aspirin or sublingual nitroglycerin if possible. For on-scene time, we selected patients who received at least one dose of prehospital aspirin or nitroglycerin. Comparison patients were attended in the same study period by primary care paramedics and vehicles not equipped with ECG machines. Only patients transported to hospital were included in our study.

\section{Prehospital ECG interpretation}

STEMI was indicated by the computer software as “***Acute MI***," with an ST segment elevation defined as at least $0.1 \mathrm{mV}$ in at least two inferior or lateral leads and at least $0.2 \mathrm{mV}$ in at least two chest leads. ${ }^{16}$ Two study cardiologists (T.H. and V.N.) retrospectively and independently reviewed the prehospital ECGs using a standardized data entry form, blinded to computerized interpretations and hospital diagnoses. They were asked whether they observed "acute ST segment elevation that would have warranted immediate consideration for reperfusion therapy," reflecting the diagnostic process required by a physician receiving a prehospital ECG from the field. ST segment elevation was defined as at least $0.1 \mathrm{mV}$ in at least two contiguous chest leads or at least two adjacent limb leads, ${ }^{17}$ not diagnostic of benign early repolarization, left bundle branch block, left ventricular hypertrophy, or pericarditis. Disagreement between the cardiologists was resolved by consensus, if possible; otherwise, a third study cardiologist (M.J.E.) independently interpreted the ECG, and the majority (twothirds) interpretation was used.

\section{Hospital diagnosis}

We requested chart information from medical records departments of the hospitals where patients were initially received (some patients were subsequently transferred). Hospital diagnosis was based on 1) the discharge summary sheet if admitted; 2) the death certificate if the patient died before admission; and 3 ) the emergency department (ED) notes if the patient was transferred or discharged from the ED. Three senior medical archivists $(>30$ years of experience each) extracted the diagnostic information, blinded to the computerized ECG interpretations, using a Microsoft Access database specifically designed for the study. The archivists completed 20 hours of training 
with the study database (supervised by L.J.B.) using a detailed manual.

Figure 1 provides details on the predefined criteria used to assign a diagnosis of STEMI. The criteria included 1) an increase in cardiac markers within 24 hours of ED arrival or 2) ST segment elevation noted in the ED notes to rule out infarctions occurring later in the hospital stay. In cases where a patient was sent to a catheterization laboratory within 4 hours of hospital arrival, without mention of STEMI or ST segment elevation in the ED notes or discharge summary, two other study cardiologists, who were distinct from the three who read the prehospital ECGs, retrospectively reviewed the first in-hospital ECG. They were asked to indicate whether ischemic ST segment elevation was definitely present, possibly present, or not present. For STEMI to be assigned, both had to specify "definitely" or "possibly" or one had to indicate "definitely" and the other "possibly."

\section{On-scene time}

On-scene time was the period between ambulance arrival at the patient encounter site and ambulance departure for the hospital. These time points were recorded by the paramedics on the vehicle computers and were later entered in a secure, internal database containing run times as part of standard operations. On-scene time thus included accessing the patient and moving him or her to the vehicle: these times were assumed not to be systematically different between the patient groups. Multivariate linear regression (on-scene time as the dependent variable) was used to adjust for patient age, patient sex, season (winter or not winter), and number of prehospital medications (one of aspirin or nitroglycerin, or both). Winter was December 1 to March 31. Outlier values (less than 5 or more than 90 minutes) were excluded because they were likely due to paramedic error. Patients without time data were also excluded. SPSS Statistics software version 17.0 (IBM, Armonk, NY) was used.

\section{RESULTS}

\section{Predictive values}

From the sample of 1,534 available prehospital ECGs, 1,247 tracings (81.3\%) were analyzed (Figure 2). The vast majority of patients presented with chest pain, with or without accompanying symptoms (Table 1).

\section{FOR PATIENTS ADMITTED AT FIRST HOSPITAL OR THOSE WHO DIED PRIOR TO ADMISSION:}

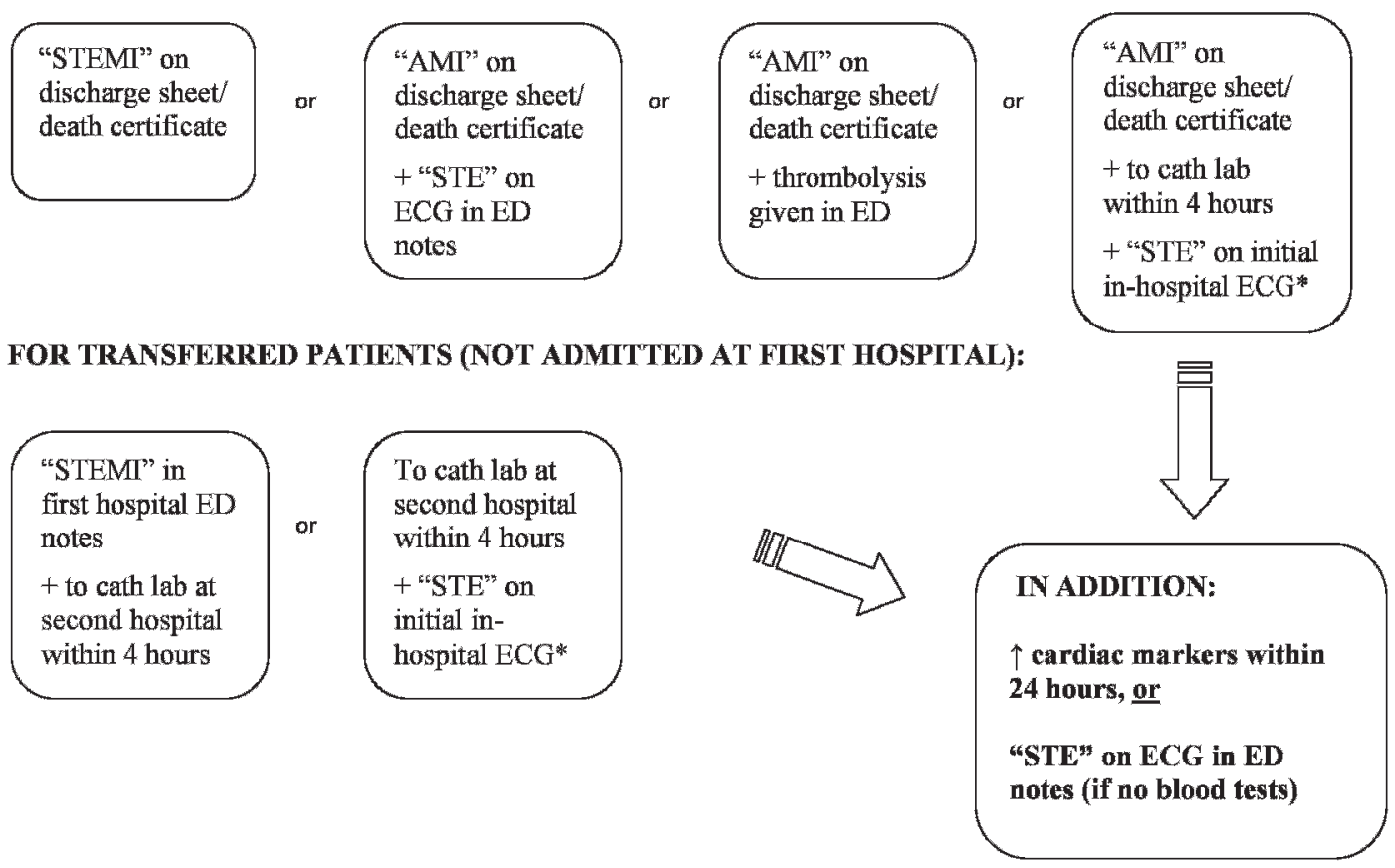

Figure 1. Criteria for assigning a hospital ST segment elevation myocardial infarction (STEMI) diagnosis. AMI = acute myocardial infarction; cath lab = catherization laboratory; ECG = electrocardiogram; ED = emergency department; STE = ST segment elevation. *According to study cardiologists. 


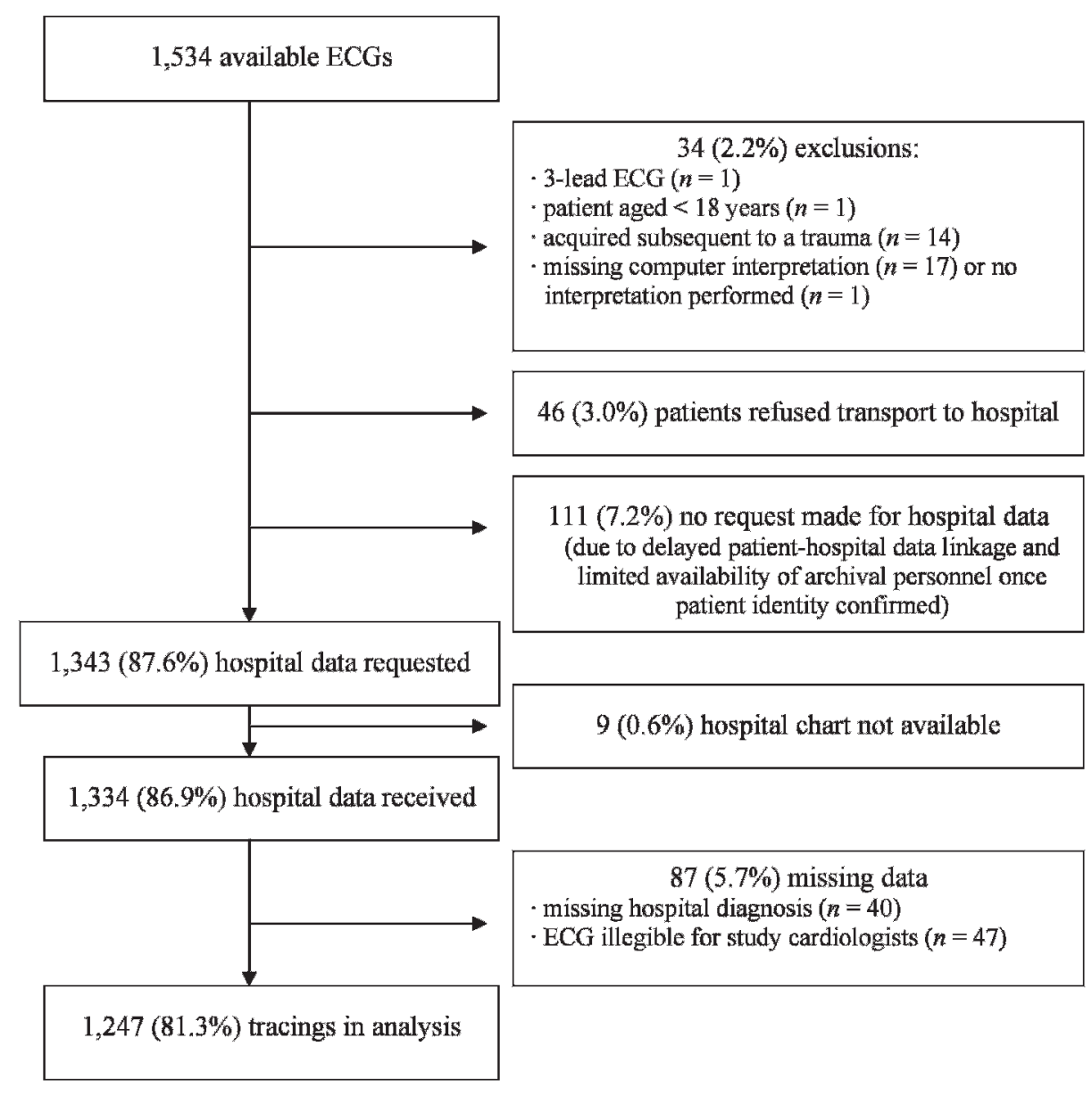

Figure 2. Exclusions and hospital data requests for predictive value analysis. ECG = electrocardiogram.

\begin{tabular}{|lr|}
\hline Table 1. Characteristics of patients in analysis of predictive values $(\mathbf{N}=\mathbf{1 , 2 4 7})$ & $n$ \\
\hline Characteristic & $66.9(15.3)$ \\
\hline Mean age, yr (SD) & $670(53.7)$ \\
Male (\%) & $730(58.5)$ \\
Prior heart disease (\%)* & \\
Principal symptom recorded by paramedics (\%) & $1,071(85.9)$ \\
$\quad$ Chest pain & $99(7.9)$ \\
Weakness/dizziness/fainting & $33(2.6)$ \\
Shortness of breath & $12(1.0)$ \\
Abdominal pain & $11(0.9)$ \\
Palpitations/tachycardia & $21(1.7)$ \\
Other &
\end{tabular}

Delay from symptom onset to prehospital ECG (min) $(n=731)$

Median (10th percentile, 90th percentile)

$88.0(26.0,339.4)$

Outcome of emergency department consultation (\%)

Admission to the first hospital

430 (34.5)

Death before hospital admission

$8(0.6)$

Transfer to second hospital

$101(8.1)$

Discharged home

$708(56.8)$

ECG $=$ electrocardiogram.

*Including unstable or stable angina, acute myocardial infarction, acute coronary syndrome, coronary artery disease, previous angioplasty or previous bypass surgery, coronary

atherosclerosis, heart ischemia, cardiac insufficiency, congestive heart failure, acute pulmonary edema, and cardiac arrest. 
The mean age of the patients was 66.9 years, and $53.7 \%$ were male; over half $(58.5 \%)$ had previous heart disease. For patients with data, delay from symptom onset to prehospital ECG varied greatly (see Table 1) but was skewed to the left (toward shorter values). For $113(9.1 \%)$ patients, more than 6 hours had elapsed before the ECG. Patients were transported to 21 hospitals; 8 (38.1\%) had cardiac catheterization facilities. About one-third of patients were admitted at the initial receiving hospital, and more than half were discharged from the ED without an admission (see Table 1).

The positive predictive value (PPV) of the computerized ECG interpretation was estimated as $74.0 \%$ (95\% credible interval [95\% CrI] 69.6-75.6) (Table 2). Thus, when the computerized interpretation was positive, there was a $26.0 \%$ probability that STEMI was absent (false positive rate). The negative predictive value (NPV) was estimated as $98.1 \%$ (95\% CrI 97.898.4), indicating a false negative rate of $1.9 \%$ (Table 2). The prevalence of STEMI in the tested population was estimated as $9.1 \%$ (95\% CrI 7.0-11.6), whereas the underlying sensitivity and specificity of the computerized interpretation were estimated as $69.2 \%$ (95\% CrI 59.0-78.5) and 98.9\% (95\% CrI 98.1-99.4), respectively (see Table 2 ).

In sensitivity analyses, the estimated predictive values changed only slightly when the proportion of STEMI patients with an ST segment elevation already present by the time of the prehospital ECG was increased (see sensitivity analysis 1 , Table 2) or the accuracy of the study cardiologists and the hospital diagnoses was made more variable (sensitivity analysis 2 ). In $2 \times 2$ table analysis, the PPV estimate raised to $79.2 \%$ (95\% confidence interval [95\% CI] 68.5-87.6) when comparing the computerized interpretation to the study cardiologists as a gold standard (sensitivity analysis 3 ). The initial interobserver agreement (kappa) for the two principal cardiologist readers (T.H. and V.N.) was 0.67 (95\% CI 0.59-0.74). We confirmed that if the cardiologists had used the software's cutoff of $0.2 \mathrm{mV}$ in the chest leads (instead of $0.1 \mathrm{mV}$ ), the same group of patients would have been identified as positive by the physicians. The most notable difference between the bayesian and $2 \times 2$ results was the uncertainty around the estimates. Compared to the $5 \%$ variation in the credible intervals, the confidence intervals had a $20 \%$ spread.

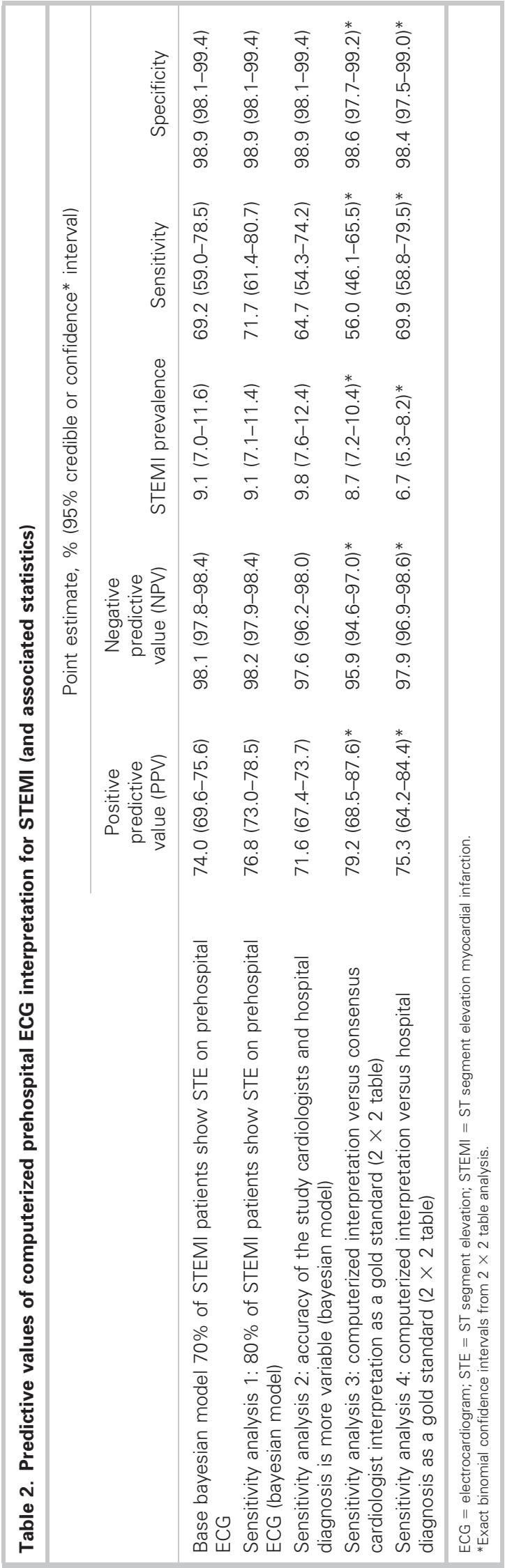




\section{On-scene time}

From the sample of 1,534 patient encounters during which a prehospital ECG was acquired, 985 patients $(64.2 \%)$ received aspirin and/or nitroglycerin and had complete time data (Figure 3). There were 5,056 comparison patients without ECGs (see Figure 3). The mean times for the largest groups of excluded patients (442 [80.5\% of those excluded] with prehospital ECGs but no documented medications and $402[51.2 \%$ of those excluded] without ECGs but missing age/sex data) were very similar to the means for the included patients in both groups (17 seconds and 4 seconds longer, respectively). Sociodemographic and seasonal data were similar across patient groups (Table 3). A slightly greater proportion of the patients without ECGs had received both medications. A prehospital ECG was associated with an adjusted 5.9 additional minutes of on-scene time (95\% CI 5.5-6.3 minutes).

\section{PATIENTS WITH ECGs}

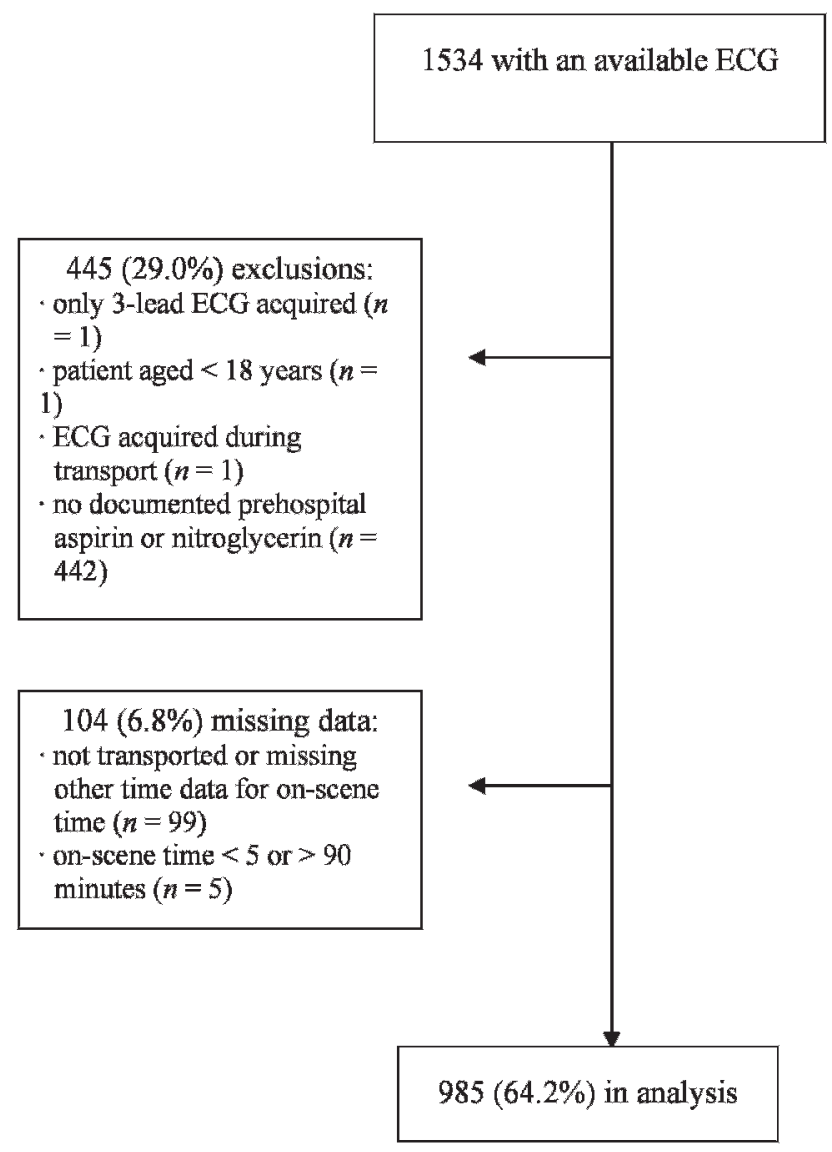

\section{DISCUSSION}

Our study provides estimates of the predictive values of computerized prehospital ECG interpretation in the BLS setting for a commonly used software. Our analysis of BLS on-scene time using concurrent controls is, to our knowledge, the largest of its kind and involved patients who were comparable in terms of presentation because they had all received prehospital medications for suspected acute coronary syndrome.

For settings with comparable ECG eligibility criteria and thus similarly low STEMI prevalence, our estimated predictive values appear adequate for the implementation of a strategy to direct patients with a positive computer result to hospitals with angioplasty facilities and patients with a negative interpretation to nonspecialized centres. The approximately 1 in 4 chance that a positive computer result is false, however, is likely too high for catheterization laboratory activation from the field. Transmission of computer-positive tracings to

\section{PATIENTS WITHOUT ECGS}

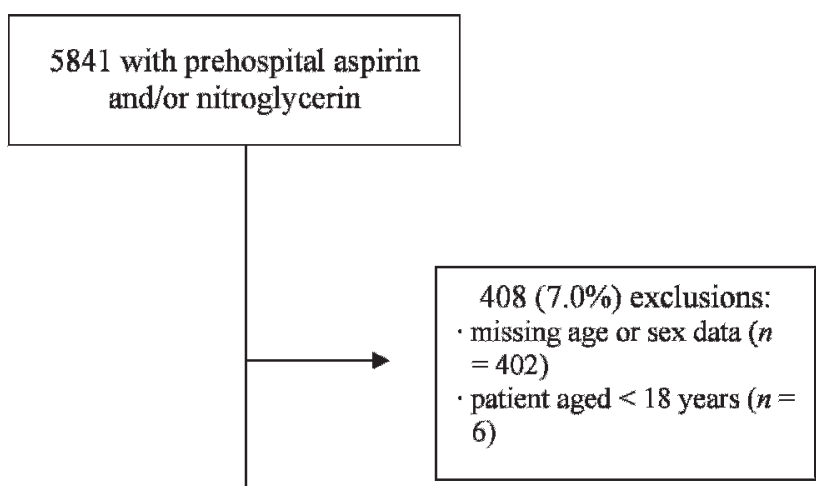

$377(6.4 \%)$ missing data: missing time data for onscene time $(n=338)$ on-scene time $<5$ or $>90$ minutes $(n=39)$

Figure 3. Exclusions of patients for on-scene time analysis. ECG = electrocardiogram. 
Table 3. Comparison of patients in analysis of on-scene time

\begin{tabular}{|c|c|c|}
\hline & $\begin{array}{c}\text { Patients with prehospital } \\
\text { ECG }(n=985)\end{array}$ & $\begin{array}{c}\text { Patients without prehospital } \\
\text { ECG }(n=5,056)\end{array}$ \\
\hline Mean age, yr (SD) & $67.4(14.6)$ & $69.3(14.8)$ \\
\hline Male, $n(\%)$ & $509(51.7)$ & $2,561(50.7)$ \\
\hline Patient encounter during winter, ${ }^{*} n(\%)$ & $333(33.8)$ & $1,713(33.9)$ \\
\hline \multicolumn{3}{|l|}{ Prehospital medication(s) received, $n(\%)$} \\
\hline Nitroglycerin only & $122(12.4)$ & $575(11.4)$ \\
\hline Aspirin only & $85(8.6)$ & $251(5.0)$ \\
\hline Both aspirin and nitroglycerin & $778(79.0)$ & $4,230(83.6)$ \\
\hline \multicolumn{3}{|l|}{ On-scene time } \\
\hline Mean (SD) & $25.2(7.1)$ & $19.5(6.4)$ \\
\hline Median (10th percentile, 90th percentile) & $24.7(17.4,33.4)$ & $18.8(12.2,27.2)$ \\
\hline Minimum, maximum & $5.3,75.5$ & $5.0,64.5$ \\
\hline Unadjusted difference in means ( $95 \%$ confidence interval) & \multicolumn{2}{|c|}{$5.8(5.3-6.2)$} \\
\hline Adjusted* difference in means (95\% confidence interval) & \multicolumn{2}{|c|}{$5.9(5.5-6.3)$} \\
\hline
\end{tabular}

physicians for overread or paramedic ECG interpretation is likely to decrease but not eliminate unnecessary activation: false positive rates of 9 to $14 \%$, based on angiographic findings, have been documented for physicians, ${ }^{18-22}$ with similar reported rates for paramedics $\left(8.3-18 \%\right.$, versus physician reading, ${ }^{23-25}$ and $12 \%$, versus angiography ${ }^{26}$ ). Thus, we estimate that computerized interpretation is associated with an excess of 10 to $15 \%$ false positives. A policy maker would have to balance the gain in PPV against the technological, logistical, and cost implications of other strategies. ${ }^{27}$

Policy makers also need to keep in mind that increasingly broad prehospital ECG eligibility criteria, incorporating more atypical STEMI presentations, will decrease PPV and thus increase the false positive rate of a computerized interpretation as a result of the lower STEMI prevalence in the tested population. ${ }^{3}$ On the other hand, very strict criteria will decrease NPV and increase the chance that a computer-negative result is false. Our ECG criteria were between these extremes, including anginal equivalents of chest pain and some atypical presentations (the latter for 14\% of our sample). Predictive values are also related to the underlying sensitivity and specificity of the test. It should be noted that our estimate of the sensitivity of the computerized interpretation was moderate. The estimated $2 \%$ chance that a negative computer result was false is not equivalent to missing $2 \%$ of STEMI cases overall.
A study of 912 ambulance patients suspected of acute coronary syndrome found a PPV of $81 \%$ and an NPV of only $89 \%$ for the same computer software studied here. ${ }^{4}$ Using an earlier version of this software, a study of 1,189 chest pain patients reported a PPV of $94 \%$ and an NPV of $81 \% .^{28}$ The STEMI prevalence in both investigations was high, at about $33 \%$, and both studies used $2 \times 2$ tables, comparing the computer to hospital diagnosis. A study of 161 computer-positive tracings from ALS ambulances ${ }^{29}$ in a low-prevalence setting (5\% STEMI; 95\% CrI 0.7-15.3) found a PPV of only $66 \%$ (95\% CrI 58-73) when compared to hospital diagnosis. ${ }^{3}$ The computer's estimated PPV for chest pain patients $(74 \%)$ was considerably higher than for those without chest pain $(25 \%){ }^{3}$ Our PPV estimate should be considered an average across clinical presentations; for a patient with crushing retrosternal pain and previous angioplasty, for example, a false positive computerized interpretation is less likely. Finally, when we compared the computer to the consensus study cardiologists considered a gold standard, the chance that a positive computer result was false was still high, at about $20 \%$.

We found that ECG acquisition by primary care paramedics did not substantially increase on-scene time. This is consistent with a prior BLS study, in which the mean on-scene time was 5.0 minutes longer (95\% CI 3.6-6.4) for 77 ECG patients compared to 100 concurrent controls. ${ }^{13}$ Our average additional onscene time is sufficiently minor compared to potential 
time savings: prehospital ECG strategies have been associated with decreased delays from hospital arrival to reperfusion therapy of about 30 minutes for ED notification, ${ }^{5,30} 30$ to 60 minutes for catheterization laboratory activation (with or without ED bypass), ${ }^{6-8,31,32}$ and more than 60 minutes for ambulance diversion (if transport times are less than 30 minutes $\left.{ }^{1}\right)^{9,33-35}$

Several study limitations should be noted. Our sample may not contain some patients due to misplaced tracings, although such losses are likely to be random. Paramedics may have acquired ECGs from patients who were not strictly eligible. We excluded 111 patients from the predictive values analysis for whom we were unable to request hospital charts. However, we do not expect results to differ for these patients because it simply took longer to verify their identity due to clerical factors, unrelated to clinical status or receiving centre. Regarding the quality of the tracings, we excluded 47 ECGs (3.1\% of all available) that were unreadable by study cardiologists; these may contain a greater proportion of false computer-positive results. ${ }^{36}$ Our bayesian model required prior inputs of diagnostic performance on which subsequent analysis depended. Sensitivity analyses, however, showed that the results were quite robust. Since the model allowed for imperfect tests, the effect of any misclassification of the hospital diagnoses during chart review was lessened. Our predictive value results are generalizable to other settings using the same computer program only to the extent that STEMI prevalence is similar. Additional on-scene time could also relate to more time spent on history taking or acquiring vital signs in the ECG group. The speed of ECG acquisition may relate to the level of paramedic experience and the site (home versus a public space), but we did not collect these data. Finally, delay associated with ECG acquisition in our region may have reduced with even more accumulation of paramedic experience.

\section{CONCLUSION}

Our study examined the predictive value of a commonly used software for the interpretation of prehospital ECGs, acquired in a setting where ECG eligibility criteria were broad and STEMI prevalence was accordingly low. We found that the computerized interpretation had high specificity but moderate sensitivity. PPV was also moderate; the high computer false positive rate may lead to excessive activation of a catheterization laboratory. This last finding, which was robust in our sensitivity analysis, is likely generalizable to other jurisdictions if similar prehospital ECG eligibility criteria are used. The acquisition of prehospital ECGs does not substantially increase on-scene time in the BLS setting.

Acknowledgements: We thank the medical directors at Urgences-santé who were involved in the study, Drs. Marcel Boucher and Michel Loyer, as well as Eric Lareau, Patrice Ruest, Claude Desrosiers, the medical archivists (Christiane Beauchamp, Francine Ruest-Martel, and Louise St-Onge Southière), the cardiologists who reviewed in-hospital ECGs (Drs. Peter Bogaty and James Nasmith), and the dedicated team of paramedics.

Competing interests: The study received institutional funding from the Montreal Heart Institute. L.J.B. received financial support from the Urgences-santé ambulance company and the Quebec Ministry of Health during the course of the study. The research archivists were paid with funds from Urgences-santé.

\section{REFERENCES}

1. O'Connor RE, Brady W, Brooks SC, et al. Part 10: acute coronary syndromes: 2010 American Heart Association Guidelines for Cardiopulmonary Resuscitation and Emergency Cardiovascular Care. Circulation 2010;122(18 Suppl 3):S787-817, doi:10.1161/CIRCULATIONAHA.110.971028.

2. Tubaro M, Danchin N, Goldstein P, et al. Pre-hospital treatment of STEMI patients. A scientific statement of the Working Group Acute Cardiac Care of the European Society of Cardiology. Acute Card Care 2011;13:56-67, doi:10.3109/17482941.2011.581292.

3. Youngquist ST, Kaji AH, Lipsky AM, et al. A bayesian sensitivity analysis of out-of-hospital 12-lead electrocardiograms: implications for regionalization of cardiac care. Acad Emerg Med 2007;14:1165-71, doi:10.1111/j.1553-2712.2007. tb02338.x.

4. Clark EN, Sejersten M, Clemmensen P, et al. Automated electrocardiogram interpretation programs versus cardiologists' triage decision making based on teletransmitted data in patients with suspected acute coronary syndrome. Am 7 Cardiol 2010;106:1696-702, doi:10.1016/j.amjcard.2010.07. $\underline{047}$.

5. Morrison LJ, Brooks S, Sawadsky B, et al. Prehospital 12lead electrocardiography impact on acute myocardial infarction treatment times and mortality: a systematic review. Acad Emerg Med 2006;13:84-9, doi:10.1111/j.1553-2712.2006. tb00989.x.

6. Brown JP, Mahmud E, Dunford JV, et al. Effect of prehospital 12-lead electrocardiogram on activation of the cardiac catheterization laboratory and door-to-balloon time in STsegment elevation acute myocardial infarction. Am 7 Cardiol 2008;101:158-61, doi:10.1016/j.amjcard.2007.07.082.

7. Caudle JM, Piggott Z, Dostaler S, et al. Impact of a rapid access protocol on decreasing door-to-balloon time in acute ST elevation myocardial infarction. CFEM 2009;11:29-35. 
8. Hutchison AW, Malaiapan Y, Jarvie I, et al. Prehospital 12lead ECG to triage ST-elevation myocardial infarction and emergency department activation of the infarct team significantly improves door-to-balloon times: ambulance Victoria and MonashHEART Acute Myocardial Infarction (MonAMI) 12-lead ECG project. Circ Cardiovasc Interv 2009;2:528-34, doi:10.1161/CIRCINTERVENTIONS.109.892372.

9. Sejersten M, Sillesen M, Hansen PR, et al. Effect on treatment delay of prehospital teletransmission of 12-lead electrocardiogram to a cardiologist for immediate triage and direct referral of patients with ST-segment elevation acute myocardial infarction to primary percutaneous coronary intervention. Am 7 Cardiol 2008;101:941-6, doi:10.1016/ j.amjcard.2007.11.038.

10. Drew BJ, Sommargren CE, Schindler DM, et al. A simple strategy improves prehospital electrocardiogram utilization and hospital treatment for patients with acute coronary syndrome (from the ST SMART Study). Am 7 Cardiol 2011; 107:347-52, doi:10.1016/j.amjcard.2010.09.027.

11. Clemmensen P, Sejersten M, Sillesen M, et al. Diversion of ST-elevation myocardial infarction patients for primary angioplasty based on wireless prehospital 12-lead electrocardiographic transmission directly to the cardiologist's handheld computer: a progress report. 7 Electrocardiol 2005;38(4 Suppl):194-8.

12. Turnipseed SD, Amsterdam EA, Laurin EG, et al. Frequency of non-ST-segment elevation injury patterns on prehospital electrocardiograms. Prehosp Emerg Care 2010;14: 1-5, doi:10.3109/10903120903144924.

13. Provo TA, Frascone RJ. 12-Lead electrocardiograms during basic life support care. Prehosp Emerg Care 2004;8:212-6.

14. Dendukuri N, Joseph L. Bayesian approaches to modeling the conditional dependence between multiple diagnostic tests. Biometrics 2001;57:158-67, doi:10.1111/j.0006-341X. 2001.00158.x.

15. Dendukuri N, Hadgu A, Wang L. Modeling conditional dependence between diagnostic tests: a multiple latent variable model. Stat Med 2009;28:441-61, doi:10.1002/ sim.3470.

16. GE Medical Systems. $12 \mathrm{SL}^{\mathrm{TM}}$ physician's guide. Milwaukee (WI): GE Medical Systems Information Technologies; 2000.

17. Antman EM, Anbe DT, Armstrong PW, et al. ACC/AHA guidelines for the management of patients with ST-elevation myocardial infarction; a report of the American College of Cardiology/American Heart Association Task Force on Practice Guidelines (Committee to Revise the 1999 Guidelines for the Management of Patients with Acute Myocardial Infarction). 7 Am Coll Cardiol 2004;44:E1-211, doi:10.1016/i.jacc.2004.07.014.

18. Larson DM, Menssen KM, Sharkey SW, et al. "Falsepositive" cardiac catheterization laboratory activation among patients with suspected ST-segment elevation myocardial infarction. FAMA 2007;298:2754-60, doi:10.1001/jama.298. 23.2754.

19. Barge-Caballero E, Vázquez-Rodríguez JM, EstévezLoureiro R, et al. Prevalence, etiology and outcome of catheterization laboratory false alarms in patients with suspected ST-elevation myocardial infarction. Rev Esp Cardiol 2010;63:518-27, doi:10.1016/S0300-8932(10)70113-5.

20. Willson AB, Mountain D, Jeffers JM, et al. Door-to-balloon times are reduced in ST-elevation myocardial infarction by emergency physician activation of the cardiac catheterisation laboratory and immediate patient transfer. Med 7 Aust 2010; 193:207-12.

21. Youngquist ST, Shah AP, Niemann JT, et al. A comparison of door-to-balloon times and false-positive activations between emergency department and out-ofhospital activation of the coronary catheterization team. Acad Emerg Med 2008;15:784-7, doi:10.1111/j.1553-2712. 2008.00186.x.

22. Davis DP, Graydon C, Stein R, et al. The positive predictive value of paramedic versus emergency physician interpretation of the prehospital 12-lead electrocardiogram. Prehosp Emerg Care 2007;11:399-402, doi:10.1080/109031207015 36784.

23. Lee C, Van Gelder CM, Cone DC. Early cardiac catheterization laboratory activation by paramedics for patients with ST-segment elevation myocardial infarction on prehospital 12-lead electrocardiograms. Prehosp Emerg Care 2010;14:153-8, doi:10.3109/10903120903537213.

24. Young DR, Murinson M, Wilson C, et al. Paramedics as decision makers on the activation of the catheterization laboratory in the presence of acute ST-elevation myocardial infarction. I Electrocardiol 2010;44:18-22, doi:10.1016/j. jelectrocard.2010.06.010.

25. Le May MR, Dionne R, Maloney J, et al. Diagnostic performance and potential clinical impact of advanced care paramedic interpretation of ST-segment elevation myocardial infarction in the field. Can 7 Emerg Med 2006;8:401-7.

26. Cheskes S, Turner L, Foggett R, et al. Paramedic contact to balloon in less than 90 minutes: a successful strategy for STsegment elevation myocardial infarction bypass to primary percutaneous coronary intervention in a Canadian emergency medical system. Prehosp Emerg Care 2011;15:490-8, doi:10.3109/10903127.2011.598613.

27. Adams G, Abusaid G, Lee B, et al. From theory to practice: implementation of pre-hospital electrocardiogram transmission in ST-elevation myocardial infarction - a multicenter experience. 7 Invasive Cardiol 2010;22:520-5.

28. Kudenchuk PJ, Ho MT, Weaver WD, et al. Accuracy of computer-interpreted electrocardiography in selecting patients for thrombolytic therapy. MITI Project Investigators. 7 Am Coll Cardiol 1991;17:1486-91, doi:10.1016/0735-1097(91) 90636-N.

29. Eckstein M, Cooper E, Nguyen T, et al. Impact of paramedic transport with prehospital 12-lead electrocardiography on door-to-balloon times for patients with STsegment elevation myocardial infarction. Prehosp Emerg Care 2009;13:203-6, doi:10.1080/10903120802472020.

30. Diercks DB, Kontos MC, Chen AY, et al. Utilization and impact of pre-hospital electrocardiograms for patients with acute ST-segment elevation myocardial infarction: data from the NCDR (National Cardiovascular Data Registry) ACTION (Acute Coronary Treatment and Intervention Outcomes Network) Registry. 7 Am Coll Cardiol 2009;53: 161-6, doi:10.1016/j.jacc.2008.09.030.

31. Rao A, Kardouh Y, Darda S, et al. Impact of the prehospital ECG on door-to-balloon time in ST elevation myocardial infarction. Catheter Cardiovas Interv 2010;75:174-8, doi:10. 1002/ccd.22257.

32. Baran KW, Kamrowski KA, Westwater JJ, et al. Very rapid treatment of ST-segment-elevation myocardial infarction: 
utilizing prehospital electrocardiograms to bypass the emergency department. Circ Cardiovasc Qual Outcomes 2010; 3:431-7, doi:10.1161/CIRCOUTCOMES.110.942631.

33. Ortolani P, Marzocchi A, Marrozzini C, et al. Pre-hospital ECG in patients undergoing primary percutaneous interventions within an integrated system of care: reperfusion times and long-term survival benefits. EuroIntervention 2011; 7:449-57, doi:10.4244/EIJV7I4A74.

34. Zanini R, Aroldi M, Bonatti S, et al. Impact of prehospital diagnosis in the management of ST elevation myocardial infarction in the era of primary percutaneous coronary intervention: reduction of treatment delay and mortality. 7 Cardiovasc Med (Hagerstown) 2008;9:570-5, doi:10.2459/ JCM.0b013e3282f2c9bd.

35. Sivagangabalan G, Ong AT, Narayan A, et al. Effect of prehospital triage on revascularization times, left ventricular function, and survival in patients with ST-elevation myocardial infarction. Am 7 Cardiol 2009;103:907-12, doi:10. 1016/j.amjcard.2008.12.007.

36. Swan PY, Nighswonger B, Boswell GL, et al. Factors associated with false positive emergency medical services triage for percutaneous coronary intervention. West 7 Emerg Med 2009;10:208-12.

37. Schull MJ, Vermeulen MJ, Stukel TA. The risk of missed diagnosis of acute myocardial infarction associated with emergency department volume. Ann Emerg Med 2006;48: 647-55, doi:10.1016/j.annemergmed.2006.03.025.

38. Pope JH, Aufderheide TP, Rothazer R, et al. Missed diagnoses of acute cardiac ischemia in the emergency department. N Engl 7 Med 2000;342:1163-70, doi:10.1056/ NEJM200004203421603.

39. Kudenchuk PJ, Maynard C, Cobb LA, et al. Utility of the prehospital electrocardiogram in diagnosing acute coronary syndromes: the Myocardial Infarction Triage and Intervention (MITI) Project. 7 Am Coll Cardiol 1998;32:17-27, doi:10.1016/ S0735-1097(98)00175-2.

40. Feldman JA, Brinsfield K, Bernard S, et al. Real-time paramedic compared with blinded physician identification of ST-segment elevation myocardial infarction: results of an observational study. Am 7 Emerg Med 2005;23:443-8, doi:10.1016/j.ajem.2004.10.011.

41. Sejersten M, Young D, Clemmensen P, et al. Comparison of the ability of paramedics with that of cardiologists in diagnosing ST-segment elevation acute myocardial infarction in patients with acute chest pain. Am 7 Cardiol 2002;90: 995-8, doi:10.1016/S0002-9149(02)02685-1.

42. Joseph L, Gyokos T, Coupal L. Bayesian estimation of disease prevalence and the parameters of diagnostic tests in the absence of a gold standard. Am 7 Epidemiol 1995;141:263-72.

43. Verbeek PR, Ryan D, Turner L, et al. Serial prehospital 12lead electrocardiograms increase identification of ST-segment elevation myocardial infarction. Prehosp Emerg Care 2012;16: 109-14, doi:10.3109/10903127.2011.614045.

\section{Appendix: Details Regarding the Analysis of Predictive Values}

A bayesian latent class model ${ }^{14,15}$ was constructed that incorporated the results of all three tests (i.e., computerized prehospital ECG interpretation, consensus cardiologist prehospital ECG interpretation, and hospital diagnosis), without making any comparisons to a gold standard. This analysis required specification of prior distributions for the diagnostic performance of all three tests (in terms of sensitivity and specificity) and for the prevalence of STEMI in the tested population. In bayesian analysis, prior information is combined with study data to form overall ("posterior") estimates of parameters of interest, which account for all inherent uncertainty, including the lack of a gold standard reference test.

A latent class model was designed to capture the following elements:

1. Patient status evolves over time; the clinical picture of developing ST segment changes at the time of the prehospital ECG can differ from that in hospital.

2. ECG interpretation by human readers and hospital diagnoses can be imperfect.

3. Computer and study cardiologist interpretations were based on the same ECG data.

4. Hospital diagnoses were based on more information than the prehospital ECG, such as physical examination, symptoms, cardiac enzymes, subsequent ECGs, and diagnostic imaging.

The statistical model was structured to include two latent variables. A latent variable represents the unknown true status of each patient ("positive" or "negative") for each state of interest. The assumptions of the model were the following:

1. None of the three tests had perfect sensitivity or specificity.

2. Since they were both interpreting the prehospital ECG data, the computer software and the cardiologists were measuring the true prehospital ECG status (i.e., whether ischemic ST segment elevation was present or absent at that time), and the true prehospital ECG status is unknown. This was latent variable 1.

3. Since the hospital diagnoses were based on more data, the hospitals were measuring the true disease status (i.e., whether acute STEMI was present or absent at the hospital), and the true disease status is unknown. This was latent variable 2.

4. The probability that a patient presenting with true STEMI in an ED showed an ischemic ST segment elevation on a prehospital ECG was $70 \% .^{28}$ 
Table A1. Prior distributions for sensitivity and specificity of consensus cardiologist prehospital ECG interpretation and hospital diagnosis

\begin{tabular}{lcc} 
& & $95 \%$ range in specificity \\
\hline Cardiologist interpretation (base model) & 95\% range in sensitivity & $0.80-0.92$ \\
Cardiologist interpretation, wider distributions (sensitivity analysis 2) & $0.85-0.95$ & $0.80-0.99$ \\
Hospital diagnosis (base model) & $0.80-0.98$ & $0.85-0.97$ \\
Hospital diagnosis, wider distributions (sensitivity analysis 2) & $0.65-0.99$ & $0.70-0.99$ \\
\hline ECG = electrocardiogram. & & \\
\end{tabular}

5. The prior distributions for the sensitivities and specificities of the cardiologists and the hospitals for detection of ischemic ST segment elevation and STEMI, respectively, were as specified in Table A1, based on literature review $w^{37-41}$ and the expert opinion, elicited before the analysis, of the three study cardiologists who were not the principal readers of the prehospital ECGs. For all analyses, low-information uniform densities were used for the prior distributions of the computer's test performance, whereby all values of sensitivity and specificity were a priori equally likely.

6. The prior distribution for the underlying prevalence of STEMI in the tested population was specified to be in a wide interval of 0.5 to $20 \%$, based on a published review of the literature. ${ }^{3}$

The prior information about the diagnostic performance of the cardiologists and the hospitals was expressed in the form of $\beta$ distributions. ${ }^{42}$ The ranges in sensitivity and specificity were considered to be equal-tailed $95 \%$ probability intervals, with the centre of the range as the mean of the distribution and onequarter of the total range as the standard deviation. The $\alpha$ and $\beta$ parameters for the distributions were calculated from these means and standard deviations using a standard formula. BayesLatentClassModels software version 1.3 was used. This software implements a Gibbs sampler to generate the posterior estimates; the first 500 iterations were used as burn-in, and the last 10,000 were used for the analysis.

Sensitivity analyses were performed to examine the impact of certain assumptions on the predictive value results. First, we increased the probability of a patient with true STEMI showing ST segment elevation on a prehospital ECG from 70 to $80 \%$ based on a recent study of serial prehospital ECGs ${ }^{43}$ Next, the prior distributions for the diagnostic performance of the cardiologists and the hospitals were widened, as specified in Table A1. The wider probabilities were chosen prior to the analysis on the basis of the expert opinion of the three study cardiologists who were not the principal prehospital ECG readers. These clinicians were asked for their opinion on the worst and best possible diagnostic performance of each test in order to assign a lower and an upper limit, respectively, for each parameter. Finally, we carried out traditional $2 \times 2$ table analyses comparing the computerized ECG interpretations to 1) the consensus cardiologist ECG interpretations as a gold standard reference and 2) the hospital diagnoses as a gold standard reference. 